\title{
Field-based observations of regional-scale, temporal variation in net primary production in Tibetan alpine grasslands
}

\author{
Y. Shi ${ }^{1}$, Y. Wang ${ }^{1}$, Y. Ma ${ }^{1}$, W. Ma ${ }^{3}$, C. Liang ${ }^{3}$, D. F. B. Flynn ${ }^{2,4}$, B. Schmid ${ }^{4}$, J. Fang ${ }^{1}$, and J.-S. He ${ }^{1,2}$ \\ ${ }^{1}$ Department of Ecology, College of Urban and Environmental Sciences, and Key Laboratory for Earth Surface Processes of \\ the Ministry of Education, Peking University, 5 Yiheyuan Rd., 100871 Beijing, China \\ ${ }^{2}$ Key Laboratory of Adaptation and Evolution of Plateau Biota, Northwest Institute of Plateau Biology, Chinese Academy of \\ Sciences, 23 Xinning Rd., 810008 Xining, China \\ ${ }^{3}$ Department of Ecological Sciences, College of Life Sciences, Inner Mongolia University, 010021 Hohhot, China \\ ${ }^{4}$ Institute of Evolutionary Biology and Environmental Studies, University of Zurich, Winterthurerstr. 190, 8057 Zurich, \\ Switzerland
}

Correspondence to: J.-S. He (jshe@pku.edu.cn)

Received: 10 August 2013 - Published in Biogeosciences Discuss.: 29 October 2013 Revised: 27 February 2014 - Accepted: 27 February 2014 - Published: 9 April 2014

\begin{abstract}
Net primary production (NPP) is a fundamental process of natural ecosystems. Temporal variation of NPP not only reflects how communities respond to environmental fluctuations, but it also has important implications for regional carbon assessment. Unfortunately, studies based on field measurements to directly address this issue in the extreme environment of alpine grasslands are rare. In this study, we measured aboveground NPP (ANPP) and species richness in 40 sites across the Tibetan alpine grasslands from 2006 to 2009 to investigate the regional pattern of temporal variation in ANPP and to quantify the effects of climate fluctuation and biodiversity on this variation. The results showed that, during the 4-year period, the average ANPP varied 1.5-fold, from 83.9 to $125.7 \mathrm{~g} \mathrm{~m}^{-2}$, with a mean coefficient of variation of temporal variation of $36.6 \%$ across the 40 sites. Compared with other studies, alpine grasslands are not more sensitive to climate fluctuations than other grassland types. Aboveground NPP exhibited synchronous temporal variation and consistent spatial patterns over the 4-year period due to the regionally similar climatic fluctuations caused by monsoondominated plateau climate. Surprisingly, rainfall fluctuation had a more profound effect on the ANPP dynamics than temperature variation, which suggests that production in the Tibetan alpine grasslands is primarily driven by precipitation. Therefore, ANPP in the Tibetan alpine grasslands are mainly constrained by water availability. Finally, we found a reduction in interannual variation (i.e., CV) in ANPP with increas-
\end{abstract}

ing species richness of plant communities, suggesting that diversity can stabilize community production in high-altitude grasslands.

\section{Introduction}

Net primary production (NPP) is the fundamental component and the most variable part of the carbon biogeochemical cycle (McNaughton et al., 1989; Field et al., 1998; Huston and Wolverton, 2009; Zhao and Running, 2010). In natural ecosystems, NPP shows year-to-year dynamics that accord with environmental fluctuations such as climate variation, resource heterogeneity, and disturbance (Briggs and Knapp, 1995; Knapp and Smith, 2001; Muldavin et al., 2008). The characteristics of the plant community, particularly species richness and composition, also influence the temporal variability of NPP (Bai et al., 2004; Flynn et al., 2008; Roscher et al., 2011). Therefore, investigating and quantifying the interannual dynamics of NPP will provide insight into the processes by which plant communities respond to external variations (Knapp and Smith, 2001; Oesterheld et al., 2001; Weber et al., 2009) and improve predictions of the potential responses of ecosystem function to global change (Ma et al., 2010b; La Pierre et al., 2011).

Temporal dynamics of NPP may challenge the robustness of large-scale patterns of vegetation productivity that 
have been described based on one-time surveys. In ecological research, transect sampling designs can amass considerable data and are often used for large-scale field surveys (e.g., Williams and Rastetter, 1999; Yang et al., 2009; Ma et al., 2010a). However, temporal dynamics could potentially induce significant changes in the spatial patterns of NPP, thus reducing the validity of generalizing across years from 1-year transect sampling. For example, highly productive communities may be susceptible to climatic fluctuations and thus experience lower production in response to drought or cold damage. Even if such incidents affect only a subset of sites during a 1-year transect survey, biased conclusions might be reached. Hence, it is necessary to use methods, such as multi-year surveys, which incorporate temporal variation into investigations of large-scale patterns of ecosystem productivity.

Worldwide, grasslands are dominant ecosystems that cover nearly $25 \%$ of the earth's land surface (e.g., Lauenroth, 1979; Parton et al., 1995; Scurlock and Hall, 1998; Hui and Jackson, 2006). Moreover, grasslands are mainly distributed across arid and semi-arid regions and exhibit high sensitivity to environmental change as well as temporally dynamic production (Knapp et al., 2002; Shaw et al., 2002; Nippert et al., 2006). Thus, a number of studies of grasslands have investigated temporal variability in production and the factors that influence it (e.g., Briggs and Knapp, 1995; Niklaus et al., 2001; Oesterheld et al., 2001; Weber et al., 2009). However, most of these studies have been conducted in temperate and tropical grasslands; very few have focused on alpine grasslands where difficulties with accessibility can make revisiting the sampling sites challenging.

Alpine grasslands are the main vegetation types at high altitudes (Körner, 2003). Because of the extreme environmental condition they face, alpine grasslands are often considered more sensitive to environmental variation than other ecosystems (Theurillat and Guisan, 2001; Cui and Graf, 2009; Gao et al., 2009). In particular, temperature variation should be the main driver for the temporal variation in alpine vegetation because low temperature is believed to be the primary environmental factor constraining vegetation growth (Shaver and Jonasson, 1999; Wielgolaski and Karlsen, 2007; Cui and Graf, 2009). Nevertheless, studies on temporal variability in alpine grasslands remain very limited and are mostly based on modeling and remote sensing (e.g., Piao et al., 2006; Gao et al., 2009; Zhong et al., 2010) rather than directly observed data. Therefore, studies based on field surveys are necessary to improve our understanding of alpine grasslands.

The Tibetan Plateau is the highest and largest plateau in the world, and over $60 \%$ of the area is covered by alpine grasslands (Zhang et al., 1988; Yang et al., 2009). Moreover, a large part of the plateau has not been strongly disturbed by many anthropogenic activities such as mineral exploration, industrial pollution, and farmland reclamation. Therefore, the Tibetan Plateau is an ideal location to investigate the climate-driven, year-to-year dynamics of alpine grasslands.
Table 1. Description of the study region. Mean annual temperature (MAT), mean annual precipitation (MAP), mean growing season temperature (MGST) and mean growing season precipitation (MGSP) of the sampling sites are shown.

\begin{tabular}{ll}
\hline Parameters & Value/Range \\
\hline No. of sites & 40 \\
Longitude $\left({ }^{\circ} \mathrm{E}\right)$ & $90.80-101.48$ \\
Latitude $\left({ }^{\circ} \mathrm{N}\right)$ & $30.31-37.28$ \\
Altitude $(\mathrm{m})$ & $2925-5105$ \\
MAT $\left({ }^{\circ} \mathrm{C}\right)$ & $-5.8-2.6$ \\
$\operatorname{MGST}\left({ }^{\circ} \mathrm{C}\right)$ & $1.5-11$ \\
$\operatorname{MAP}\left(\mathrm{mm} \mathrm{yr}^{-1}\right)$ & $218-604$ \\
MGSP $\left(\mathrm{mm} \mathrm{yr}^{-1}\right)$ & $133-402$ \\
\hline
\end{tabular}

In a previous study, we addressed large-scale patterns of plant richness and productivity across Chinese grasslands (Ma et al., 2010a). Here, we extend those results to investigate the interannual variability of the Tibetan alpine grasslands based on a 4-year (2006-2009) repeated survey of 40 sites across the plateau. Thus, the objectives of this study were to (1) explore the interannual variability of ANPP of the Tibetan alpine grasslands and compare its sensitivity to climatic fluctuation with other grassland types, (2) detect the year-to-year variation in observed spatial pattern of ANPP across all 40 sites and discuss if it is necessary to make repeated surveys in large-scale studies, and (3) quantify the effects of climatic fluctuations and species diversity on the interannual variation of ANPP in the Tibetan alpine grasslands.

\section{Materials and methods}

\subsection{Site description}

This study was conducted in the alpine grasslands of the Tibetan Plateau during four separate expeditions that occurred in late July and early August from 2006 to 2009. Forty field sites along an approximately $1200 \mathrm{~km}$-long and $200 \mathrm{~km}$-wide transect in the central-eastern part of the plateau (latitudes from 30.31 to $37.28^{\circ} \mathrm{N}$, longitudes from 90.80 to $101.48^{\circ} \mathrm{E}$, and altitudes from 2925 to $5105 \mathrm{~m}$ a.s.l.) were selected for plant community surveys (Table 1, Fig. 1a). All of the sites were selected by visual inspection of the vegetation with the aim to sample sites subjected to minimize grazing and other anthropogenic disturbances. Further, for this purpose, sites were established either in deferred grazing areas or on winter pastures inside fences to minimize livestock-induced disturbances.

Across the sites and in the 50 years from 1960 to 2009, mean annual air temperature (MAT) ranged from -5.8 to $2.6{ }^{\circ} \mathrm{C}$, and mean annual precipitation (MAP) ranged from 218 to $604 \mathrm{~mm}$ (Table 1 ). The vegetation represented natural zonal grassland and included two main vegetation types: alpine steppe (18 sites, Fig. 1b) and alpine meadow (22 sites, 
Fig. 1c). Alpine steppes are dominated by short, dense tussock grasses such as Stipa purpurea and S. subsessiliflora, whereas alpine meadows consist mainly of perennial tussock sedges such as Kobresia pygmaea, K. humilis, and K. tibetica (Zhang et al., 1988).

\subsection{Data collection}

We collected data on plant community biomass and species richness from all of the sites for each year from 2006 to 2009. The geographical coordinates, elevation and vegetation type of each site were recorded. Sampling sequence was consistent between years. According to the observed climate data from 49 meteorological stations across the Tibetan alpine grasslands, the temporal fluctuations in temperature and precipitation during the study period represented more than $80 \%$ of the ranges of the climate records over the past three decades, from 1980-2009 (Fig. 2). Thus, our study could well reflect recent past climate fluctuations.

During the 2006 expedition, we positioned a $10 \times 10 \mathrm{~m}$ plot at each site and established three quadrats along the diagonal line of each plot. In each quadrat, one sampling square $(1 \times 1 \mathrm{~m})$ was randomly selected to measure aboveground plant community biomass and species richness. Previous studies have proved that this survey method is sufficient to represent the biomass and biodiversity of alpine grasslands on the Tibetan Plateau (Wang et al., 2006; Fan et al., 2009; Ma et al., 2010a). All of the vascular plant species in each sampling square were counted to obtain a measure of species richness (SR). After the community survey, we collected the aboveground biomass in all three squares. The harvested biomass was measured by first oven-drying the sample at $60^{\circ} \mathrm{C}$ and then weighing it to the nearest $0.1 \mathrm{~g}$. This late July/early August, aboveground biomass was used as a proxy for aboveground NPP (Sala et al., 2000; Luo et al., 2004, 2009). In the following three expeditions, from 2007 to 2009 , we used the same protocol in the same $10 \times 10 \mathrm{~m}$ plots but located sampling squares away from the previous ones to eliminate the influences of the harvest.

Climate data used in this study included annual temperature (AT), annual precipitation (AP), growing season temperature (GST, from April to August) and growing season precipitation (GSP) from 2006 to 2009. As in our previous articles, these data were calculated based on a cokriging method that uses a $2 \mathrm{~km}$-resolution digital elevation model (DEM) from monthly temperature and precipitation records (20062009) at 752 well-distributed climate stations across China as a covariate (Yang et al., 2008a; He et al., 2009). As shown in Fig. S1 of the Supplement, air temperature interpolated in this way correlates significantly with $10 \mathrm{~cm}$ soil temperatures measured in situ by soil thermal probes (Hobo U12, Onset Computer Corp., MA, USA) at 33 sites and we are thus confident that the interpolation of air temperatures is appropriate for the purpose of this study.

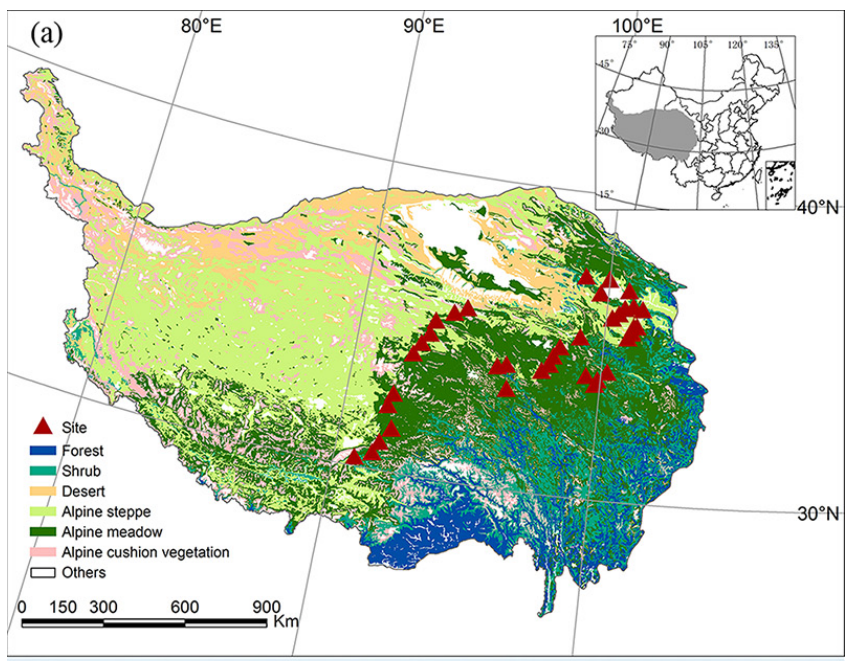

(b)

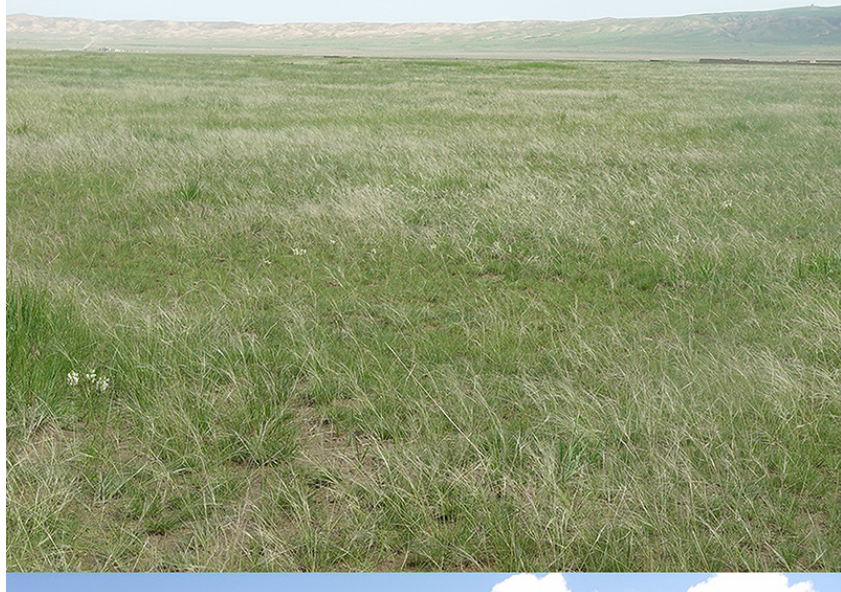

(c)

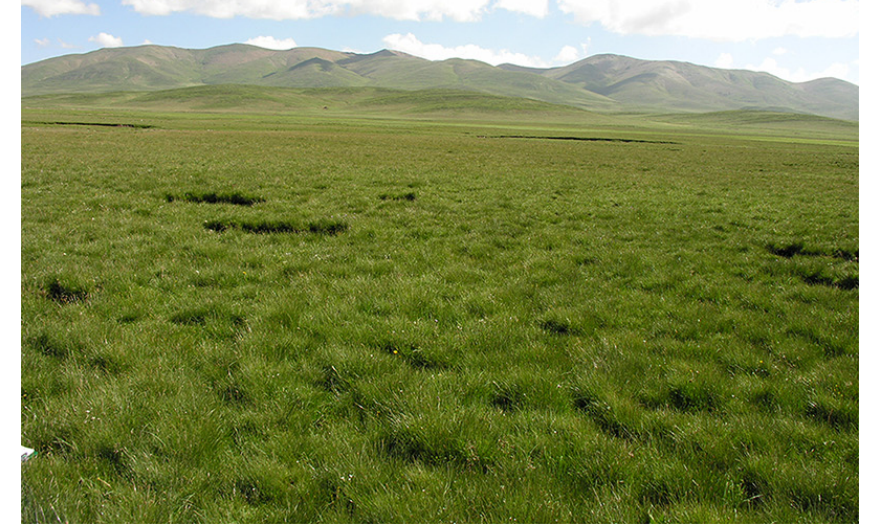

Fig. 1. Geographical distribution of the sampling sites against the background map of the vegetation of the Tibetan Plateau (1: 1000000 ; Chinese Academy of Sciences, 2001) (a), the landscape of alpine steppe (b) and alpine meadow (c) (photo by Jin-Sheng $\mathrm{He})$. 

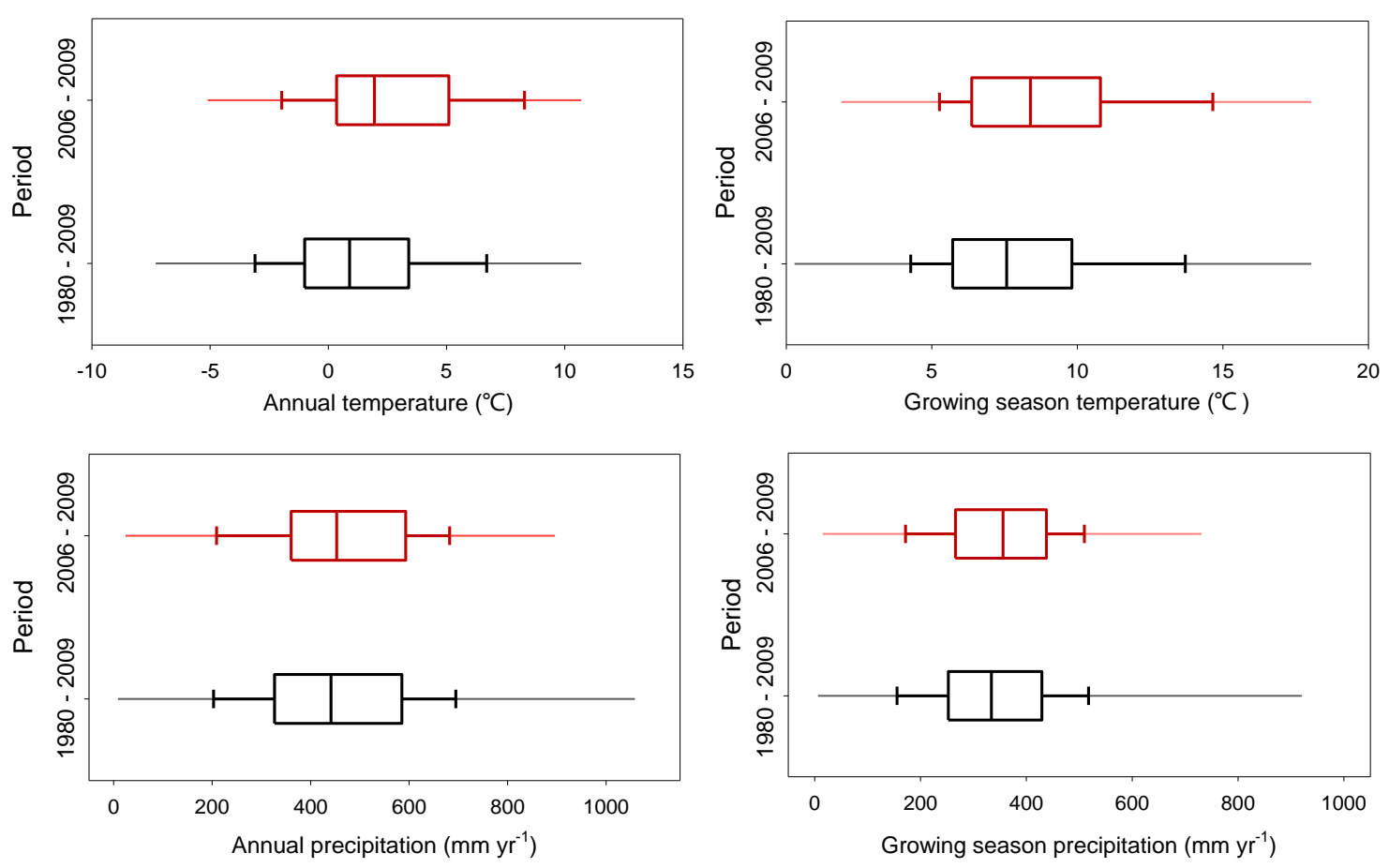

Fig. 2. Box plots of annual temperature, annual precipitation, growing season temperature and growing season precipitation collected from 49 meteorological stations during the current period of study (2006-2009) and 30 years (1980-2009) in the past. The box plots show the median, quartiles and 10th and 90th percentiles of the climatic variables.

\subsection{Statistical analyses}

The mean ANPP and species richness of three quadrats for each year were taken as site-level data and used in the analysis. For each site, the coefficient of variation (CV) of ANPP (abbreviated to $\mathrm{CV}_{\mathrm{ANPP}}$ ) over the 4-year period was used to express the interannual variation in aboveground NPP, and the 4-year average SR was taken as the measurement of species richness.

A repeated measures ANOVA was used to detect the effect of vegetation type on ANPP and to compare the differences across years in ANPP for the whole study region or within a vegetation type. To detect whether the spatial pattern of aboveground NPP changed over time, we performed typeII regressions (major axis regressions) and rank regressions (Culver et al., 2003; Stoch et al., 2009) between the ANPP of different years. We assumed that the rank of ANPP for each site would remain the same over all 4 years if the spatial pattern did not change. If both regression relationships were significant and slopes of the rank regression lines did not strongly differ from one, we could conclude that the temporal variation in the spatial pattern of ANPP was weak.

Further, analysis of covariance (ANCOVA) was conducted to test for temporal changes in the relationships between climate factors, species richness and aboveground net primary production across the study region. Ordinary least squares (OLS) regression was used to investigate the relationships between climatic fluctuations, species richness and temporal variation of aboveground NPP. Finally, general linear models (GLMs) were used to quantify effect strengths. Climate factors used in our analysis included AT, AP, GST, and GSP. The magnitudes of these factors were measured by their CVs, following the same method as for temporal variation of ANPP (abbreviated as $\mathrm{CV}_{\mathrm{AT}}, \mathrm{CV}_{\mathrm{AP}}, \mathrm{CV}_{\mathrm{GST}}$, and $\mathrm{CV}_{\mathrm{GSP}}$, respectively). Due to collinearity between AT/GST and AP/GSP, both ANCOVAs and GLMs were built using either the annual climate data or the growing season climate data.

All statistical analyses were performed using R 2.13.2 (2011). The tests of slope in rank regression were achieved using the R package smatr.

\section{Results}

\subsection{General patterns of ANPP over the 4 study years}

Across all 40 sites, the mean annual ANPP was 109.9, 91.2, 83.9 , and $125.7 \mathrm{~g} \mathrm{~m}^{-2}$ in 2006, 2007, 2008, and 2009, respectively, with corresponding standard deviations (SD) of 75.13, $54.32,61.62$, and 72.01. Interannual variation of aboveground NPP $\left(\mathrm{CV}_{\mathrm{ANPP}}\right)$ over the 4-year period for each site averaged $36.6 \%$ with a range of 6.3 to $70.3 \%$ (Table 2).

On the whole, alpine meadows had higher production (with mean ANPP of 133.3, 107.9, 100.8, and $138.5 \mathrm{~g} \mathrm{~m}^{-2}$ from 2006-2009) than alpine steppes (78.3, 68.6, 60.9, and 
Table 2. Aboveground net primary production (ANPP, $\mathrm{g} \mathrm{m}^{-2}$ ) and species richness in the Tibetan grasslands from 2006-2009. Mean, standard deviation (SD) and range of observations are shown. Different letters indicate statistically significant differences at $P<0.05$. Temporal variations were calculated as the coefficient of variation of ANPP over the 4-year period.

\begin{tabular}{|c|c|c|c|c|c|}
\hline & 2006 & 2007 & 2008 & 2009 & $\begin{array}{l}\text { Temporal } \\
\text { variation }\end{array}$ \\
\hline \multicolumn{6}{|c|}{$\operatorname{ANPP}\left(\mathrm{g} \mathrm{m}^{-2}\right)$} \\
\hline \multicolumn{6}{|c|}{ Alpine meadow $(n=22)$} \\
\hline Mean & $133.3 b$ & $107.9 \mathrm{a}$ & $100.8 \mathrm{a}$ & $138.5 b$ & $31.3 \%$ \\
\hline SD & 84.90 & 56.35 & 66.96 & 80.82 & 0.16 \\
\hline Range & $40.7-330.4$ & $32.4-244.6$ & $16.3-297.8$ & $45.6-415.7$ & $6.3-70.3 \%$ \\
\hline \multicolumn{6}{|c|}{ Alpine steppe $(n=18)$} \\
\hline Mean & $78.3 b$ & $68.6 \mathrm{ab}$ & $60.9 \mathrm{a}$ & $108.4 \mathrm{c}$ & $42.4 \%$ \\
\hline SD & 44.70 & 46.05 & 46.05 & 55.72 & 0.17 \\
\hline Range & $29.9-160.5$ & $13.4-177.4$ & $8.0-158.1$ & $28.6-220.6$ & $18.0-68.6 \%$ \\
\hline \multicolumn{6}{|c|}{ Overall $(n=40)$} \\
\hline Mean & $109.9 b$ & $91.2 \mathrm{a}$ & $83.9 \mathrm{a}$ & $125.7 \mathrm{~b}$ & $36.6 \%$ \\
\hline SD & 75.13 & 54.32 & 61.62 & 72.01 & 0.17 \\
\hline Range & $29.9-330.4$ & $13.7-244.6$ & $8.0-297.9$ & $28.6-415.7$ & $6.3-70.3 \%$ \\
\hline \multicolumn{6}{|c|}{ Species richness } \\
\hline \multicolumn{6}{|c|}{ Alpine meadow $(n=22)$} \\
\hline Mean & $16.9 \mathrm{~b}$ & $15.0 \mathrm{a}$ & $14.7 \mathrm{a}$ & $17.6 \mathrm{~b}$ & $14.9 \%$ \\
\hline SD & 5.08 & 5.10 & 4.41 & 3.82 & 0.09 \\
\hline Range & $9.0-26.3$ & $8.0-26.0$ & $7.3-24.7$ & $11.0-25.7$ & $0.8-30.8 \%$ \\
\hline \multicolumn{6}{|c|}{ Alpine steppe $(n=18)$} \\
\hline Mean & $10.9 \mathrm{a}$ & $10.2 \mathrm{a}$ & $10.0 \mathrm{a}$ & $12.5 b$ & $17.5 \%$ \\
\hline SD & 4.42 & 4.34 & 3.64 & 3.72 & 0.06 \\
\hline Range & $5.3-21.3$ & $5.3-24.3$ & $5.0-20.7$ & $7.3-23.0$ & $7.4-30.5 \%$ \\
\hline \multicolumn{6}{|c|}{ Overall $(n=40)$} \\
\hline Mean & $14.2 b$ & $12.9 \mathrm{a}$ & $12.5 \mathrm{a}$ & $15.3 \mathrm{c}$ & $16.1 \%$ \\
\hline SD & 5.62 & 5.29 & 4.67 & 4.52 & 0.08 \\
\hline Range & $5.3-26.3$ & $5.3-26.0$ & $5.0-24.7$ & $7.3-25.7$ & $0.8-30.8 \%$ \\
\hline
\end{tabular}

$108.4 \mathrm{~g} \mathrm{~m}^{-2}$ from 2006 to $2009, P<0.01$ ). Across the study region, ANPP values in 2006 and 2009 were significantly higher than those in 2007 and $2008(P<0.05)$. This pattern was also evident for alpine meadows, but ANPP in 2009 was highest in alpine steppes (Table 2).

\subsection{Temporal variation of ANPP pattern across all sites}

The type-II regression indicated that annual ANPP across all 40 sites from different years was highly correlated $(P<$ 0.001 , Table 3). Further, rank regression analysis produced significant regression lines between different years $(P<$ 0.001 , Fig. 3a-f); the slopes were close to 1 , and none of them differed significantly from 1 ( $P>0.1$, Fig. 3a-f).

These results demonstrate that the sites with relatively high productivity in one year maintained relatively high productivity in other years. Despite climatic fluctuations and corresponding changes in average ANPP in our study region, the pattern of annual ANPP across all 40 sites was consistent from 2006-2009.

Meanwhile, we conducted OLS regression for climate data of 66 meteorological stations from 2006-2009 in our study region. The result showed that AT, AP, GST and GSP all exhibited highly significant linear correlations between different years $(P<0.01$, Fig. $4 \mathrm{a}, \mathrm{b})$, indicating a parallel spatial interannual variation in climate across the Tibetan Plateau.

\subsection{Influences of climatic fluctuation and species richness on the interannual variation of ANPP}

ANCOVA revealed that, across the whole region, AP, GSP, and SR all had significant relationships with ANPP. AT and GST did not have significant relationships with ANPP, and neither interacted significantly with year (Table 4).

In the OLS regression analysis, $\mathrm{CV}_{\mathrm{AT}}, \mathrm{CV}_{\mathrm{AP}}$, and $\mathrm{CV}_{\mathrm{GSP}}$ all showed significant positive relationships with $\mathrm{CV}_{\mathrm{ANPP}}$ $\left(P<0.05\right.$, Fig. 5a, b), but the site-specific $\mathrm{SR}_{\text {average }}$ over the 4-year period was negatively correlated with $\mathrm{CV}_{\mathrm{ANPP}}$ (Fig. 6).

Because AT was not a significant driver of ANPP and that $\mathrm{CV}_{\mathrm{GST}}$ was not significantly related to $\mathrm{CV}_{\mathrm{ANPP}}$, we entered rainfall factors into the GLMs first. The analysis indicated that both the model incorporating annual climate factors and species diversity (entered in sequences as $\mathrm{CV}_{\mathrm{AP}}, \mathrm{CV}_{\mathrm{AT}}$, and 
Table 3. Type II regression between ANPP of different years. Slope of regression line, $95 \%$ lower limit of slope, and $95 \%$ upper limit of slope are shown. All regression lines are highly significant $(P<0.001)$.

\begin{tabular}{lllll}
\hline $\begin{array}{l}\text { Dependent } \\
\text { variable }\end{array}$ & $\begin{array}{l}\text { Independent } \\
\text { variable }\end{array}$ & Slope & $\begin{array}{l}\text { 95\% } \\
\text { lower limit }\end{array}$ & $\begin{array}{l}95 \% \\
\text { upperlimit }\end{array}$ \\
\hline 2006 & 2007 & 1.38 & 1.09 & 1.75 \\
& 2008 & 1.22 & 1.02 & 1.45 \\
& 2009 & 1.04 & 0.84 & 1.29 \\
\hline 2007 & 2006 & 0.72 & 0.57 & 0.91 \\
& 2008 & 0.88 & 0.71 & 1.09 \\
& 2009 & 0.75 & 0.58 & 0.98 \\
\hline 2008 & 2006 & 0.82 & 0.69 & 0.98 \\
& 2007 & 1.13 & 0.91 & 1.41 \\
& 2009 & 0.86 & 0.71 & 1.03 \\
\hline 2009 & 2006 & 0.96 & 0.78 & 1.78 \\
& 2007 & 1.32 & 1.02 & 1.72 \\
& 2008 & 1.17 & 0.97 & 1.40 \\
\hline
\end{tabular}

$\left.\mathrm{SR}_{\text {average}}\right)$ and the one incorporating growing season climate factors and diversity $\left(\mathrm{CV}_{\mathrm{GSP}}, \mathrm{CV}_{\mathrm{GST}}\right.$, and $\left.\mathrm{SR}_{\text {average }}\right)$ were significant $(P<0.001)$ with multiple $R^{2}$ values of $53.3 \%$ and $32.9 \%$, respectively (Table 5).

Both models showed that climate fluctuations had relatively high explanatory power for the interannual variation in ANPP. For the model with annual climate factors as independent variables, $\mathrm{CV}_{\mathrm{AP}}, \mathrm{CV}_{\mathrm{AT}}$, and their interaction were all significant and explained $15.0 \%, 9.9 \%$ and $6.1 \%$ of the variation in ANPP, respectively. For the second model, $\mathrm{CV}_{\mathrm{GSP}}$ explained $22.8 \%$ of the total variation, whereas neither $\mathrm{CV}_{\mathrm{GST}}$ nor the interaction of the two CVs were significant (Table 5).

Finally, average species richness significantly accounted for $9 \%$ of the variation in the interannual $\mathrm{CV}$ of ANPP when $\mathrm{CV}_{\mathrm{AP}}$ and $\mathrm{CV}_{\mathrm{AT}}$ were fitted into the model. However, the influence of diversity was not significant when $\mathrm{CV}_{\mathrm{GSP}}$ and $\mathrm{CV}_{\mathrm{GST}}$ were entered as explanatory variables (Table 5).

\section{Discussion}

\subsection{The sensitivity of ANPP to climatic fluctuation in Tibetan grasslands}

Our research reported that across 4 years, interannual CV of ANPP in the Tibetan alpine grasslands is $36.6 \%$ on average. Gao et al. (2009) reported a nearly equivalent result in that the interannual variation of NPP in Northern Tibetan grasslands from 1981-2004 was 35.2\% using MODIS remote sensing data. Considering the fact that climatic fluctuations during our study period could reflect climatic fluctuations in the past, this similarity suggests that our study could be comparable to the long-term study on the Tibetan Plateau.
Generally, high-altitude vegetation is believed to be much more sensitive to climate fluctuations than other ecosystems due to the extreme environments and severe stresses, especially cold temperature (Körner et al., 1997; Theurillat and Guisan, 2001; Cui and Graf, 2009). For instance, Sala et al. (2000) used models to point out that small changes in climate could induce large changes in community composition and biodiversity in alpine and arctic ecosystems. Studies in alpine ecosystems of the European Alps have shown obvious and unexpected changes in vegetation coverage with climate change (Pauli et al., 2003; Cannone et al., 2007). Moreover, warming and biodiversity experiments in the Tibetan alpine grasslands have reported rapid and strong responses of aboveground biomass to artificial warming and species invasion (e.g., Zhang and Welker, 1996; Pfisterer et al., 2004).

Nevertheless, compared with studies in other types of grasslands, our findings suggest that the Tibetan alpine grasslands are not more sensitive than other grassland types in terms of community production. By collecting long-term production records from 118 grasslands sites across the world, Yang et al. (2008b) reported that at the global scale, the interannual CV of ANPP in grasslands had a range of 3.6-101.0\%, and CV of precipitation ranged between 3.0$40.0 \%$. Hu et al. (2007) reported that the temporal variation of ANPP in the Inner Mongolian temperate steppes had a mean of $32.8 \%$ with a range of $13.2-80.8 \%$, and temporal variation of rainfall was approximately $7-28 \%$. Obviously, the temporal variability of aboveground net primary production in our study is similar to that found in previous studies, whereas environmental fluctuation, mainly expressed by variation in precipitation, is similar to or greater than that in prior studies.

Such relative stability in productivity in the face of environmental variation could arise from the large amount of 
Table 4. Summary of ANCOVA for the effects of year, climate and species richness on aboveground net production (ANPP). ${ }^{* * *} P<0.001$; ** $P<0.01$; $^{*} P<0.05$.

\begin{tabular}{lllll}
\hline Term & Df & MS & $F$ value & $P$ value \\
\hline Using annual climate data & & & & \\
Year & 3 & 2.19 & 5.76 & $<0.001^{* * *}$ \\
AT & 1 & 0.18 & 0.47 & 0.496 \\
AP & 1 & 5.23 & 13.76 & $<0.001^{* * *}$ \\
SR & 1 & 8.47 & 22.27 & $<0.001^{* * *}$ \\
Year: AT & 3 & 0.14 & 0.36 & 0.785 \\
Year: AP & 3 & 0.61 & 1.61 & 0.189 \\
Year: SR & 3 & 0.15 & 0.39 & 0.758 \\
\hline Using growing season climate data & & & & \\
Year & 3 & 2.19 & 5.62 & $0.001^{* *}$ \\
GST & 1 & 0.30 & 0.76 & 0.384 \\
GSP & 1 & 3.61 & 9.26 & $0.003^{* *}$ \\
SR & 1 & 9.20 & 23.60 & $<0.001^{* * *}$ \\
Year: GST & 3 & 0.22 & 0.57 & 0.634 \\
Year: GSP & 3 & 0.34 & 0.87 & 0.461 \\
Year: SR & 3 & 0.14 & 0.36 & 0.786 \\
\hline
\end{tabular}

Table 5. Summary of GLM for the effects of climate fluctuation and species richness (SR) on the interannual variation of aboveground primary production (ANPP). AP: annual precipitation; AT: annual temperature; GSP: growing season precipitation; GST: growing season temperature; CV: coefficient of variation; \%SS: percentage of total sum of squares explained. ${ }^{* * *} P<0.001 ;{ }^{* *} P<0.01 ;{ }^{*} P<0.05 ; \dagger$ $P<0.1$.

\begin{tabular}{llllll}
\hline Term & Df & MS & $F$ & $P$ & $\% \mathrm{SS}$ \\
\hline Using annual data & & & & & \\
$\mathrm{CV}_{\mathrm{AP}}$ & 1 & 0.17 & 10.24 & $0.003^{* *}$ & 15.0 \\
$\mathrm{CV}_{\mathrm{AT}}$ & 1 & 0.11 & 6.77 & $0.014^{*}$ & 9.9 \\
$\mathrm{SR}_{\mathrm{averag}}$ & 1 & 0.10 & 6.15 & $0.019^{*}$ & 9.0 \\
$\mathrm{CV}_{\mathrm{AP}}: \mathrm{CV}_{\mathrm{AT}}$ & 1 & 0.07 & 4.19 & $0.049^{*}$ & 6.1 \\
$\mathrm{CV}_{\mathrm{AP}}: \mathrm{SR}_{\text {average }}$ & 1 & 0.07 & 4.08 & $0.052^{\dagger}$ & 6.0 \\
$\mathrm{CV}_{\mathrm{AT}}: \mathrm{SR}_{\mathrm{average}}$ & 1 & 0.00 & 0.13 & 0.725 & 0.2 \\
$\mathrm{CV}_{\mathrm{AP}}: \mathrm{CV}_{\mathrm{AT}}: \mathrm{SR}$ average & 1 & 0.08 & 4.90 & $0.034^{*}$ & 7.2 \\
$\mathrm{Residuals}$ & 32 & 0.02 & & & 46.7 \\
\hline Using growing season data $_{\mathrm{CV}}$ & & & & & \\
$\mathrm{CV}_{\mathrm{GSP}}$ & 1 & 0.25 & 10.89 & $0.002^{* *}$ & 22.8 \\
$\mathrm{SR}_{\mathrm{average}}$ & 1 & 0.00 & 0.05 & 0.829 & 0.1 \\
$\mathrm{CV}_{\mathrm{GSP}}: \mathrm{CV}_{\mathrm{GST}}$ & 1 & 0.04 & 1.89 & 0.179 & 4.0 \\
$\mathrm{CV}_{\mathrm{GSP}}: \mathrm{SR}_{\text {average }}$ & 1 & 0.05 & 2.09 & 0.158 & 4.4 \\
$\mathrm{CV}_{\mathrm{GST}}: \mathrm{SR}_{\text {average }}$ & 1 & 0.01 & 0.62 & 0.436 & 1.3 \\
$\mathrm{CV}_{\mathrm{GSP}}: \mathrm{CV}_{\mathrm{GST}}: \mathrm{SR}$ average & 1 & 0.00 & 0.02 & 0.882 & 0.0 \\
Residuals & 32 & 0.00 & 0.11 & 0.745 & 0.2 \\
\hline
\end{tabular}

underground biomass, the long preformation of buds, and the widespread asexual clonal propagation in alpine ecosystems (Diggle et al., 1998), all of which could dampen the impacts of environmental fluctuations on ecosystem production. Thus, despite possible changes in community composition or diversity, alpine grasslands do not exhibit a high amplitude response to climatic variation in terms of ANPP.

\subsection{Synchronous regional-scale dynamics of ANPP on the plateau}

Regardless of the variation in mean aboveground NPP over the 4-year period, we found that temporal changes were synchronized among sites in the current study. As mentioned above, these results reflect consistent spatial patterns of ANPP during the time series. 

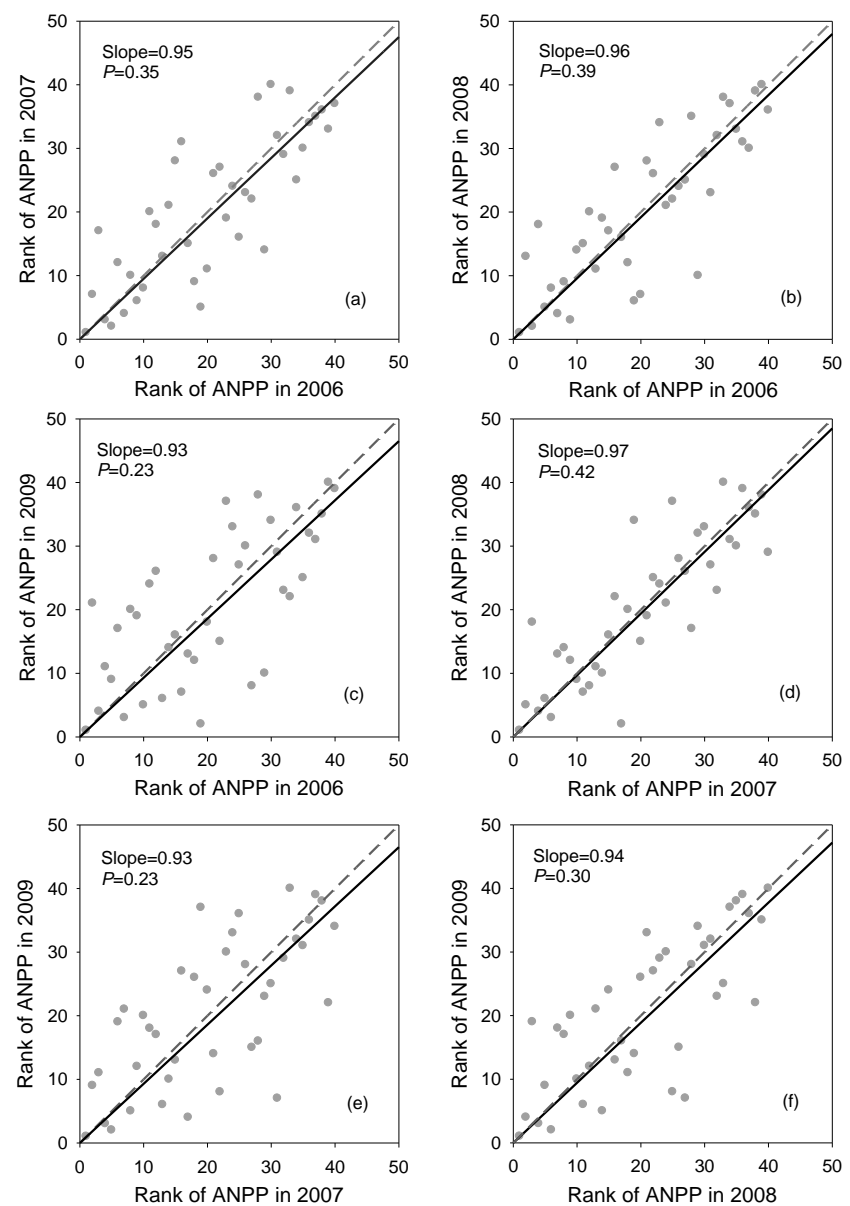

Fig. 3. The rank regression between aboveground net primary production (ANPP) for each pair of years from 2006-2009 (a-f). The slopes of the regression lines are given, and none differ significantly from 1 .

We speculate that this similarity in the spatial pattern of ANPP across sites over the 4-year period could stem from parallel climatic regimes across the whole study region. In general, environmental factors, such as climate and soil properties, are the main drivers of plant community productivity at large spatial scales (Briggs and Knapp, 1995; Knapp and Smith, 2001; Jobbagy et al., 2002; Bai et al., 2004). Particularly, climatic factors are important drivers of net primary productivity in most biomes (Sala et al., 1988; Briggs and Knapp, 1995; Tian et al., 1998; Chapin et al., 2002; Jobbagy et al., 2002). For the Tibetan Plateau, the unique plateau monsoon system that derives from changes in atmospheric pressure and circulation direction with changes in season, governs the climate on the plateau surface, and characterizes a relatively independent climate zone (Qian and Zhu, 2001; Lu et al., 2004). During the summer season, the southwest monsoon from the Indian Ocean brings more than $80 \%$ of the annual rainfall and forms a gradient of decreasing precipitation on the plateau from southeast to northwest (Lu et al., 2004;
Tian et al., 2007). In winter, the high pressure on the Tibetan Plateau drives the flow of atmospheric currents toward its surroundings and induces a cold and dry climate (Loewen et al., 2007). This monsoon climate system would induce synchronous temporal variation in temperature and precipitation at different locations across the plateau. Meteorological records also show that over the past several decades, temperature variations have been spatially consistent across the plateau (Lin and Zhao, 1996), and the rainfall has the similar temporal trends and fluctuations in most regions (Xu et al., 2008). In addition, the linear relationships for climate data of 66 meteorological stations as shown in Fig. 4 also provided evidence for the parallel climatic fluctuations on the Tibetan Plateau. Thus, the similar dynamics of aboveground NPP during the 4-year period at the different sites were most likely caused by a similar climate pattern.

Our analysis also answers the questions of whether temporal variation could induce significant changes in the spatial pattern of ANPP, and if it is necessary to make repeated, multi-year investigations for all large-scale field studies. Our study showed that if the climatic regime does not change significantly during a study period, such as on the Tibetan Plateau, interpretations based on one-time transect surveys can be representative of the pattern of net primary production even if the productivity values might vary substantially between years. Conversely, 1-year transect surveys might bias community production patterns if they are conducted across more than one climatic region, and interannual variation would have to be considered a potential caveat in the interpretations of the results.

\subsection{Precipitation overrides temperature in shaping patterns of ANPP}

At high altitudes, plant growth is often considered to be mainly limited by low growing season temperature (Körner, 2003), so consequently, fluctuation in temperature should be more important than precipitation in determining the temporal variation in alpine vegetation (Shaver and Jonasson, 1999; Wielgolaski and Karlsen, 2007). A number of experiments in alpine and arctic ecosystems also presented that warming, either due to nature or treatment, would induce significant increases in plant biomass (Schäppi, 1996; Schäppi and Körner, 1996; Van Wijk et al., 2004; Walker et al., 2006). However, our ANCOVA showed that on the Tibetan Plateau, temperature factors do not significantly predict ANPP, and variation in precipitation has higher explanatory power in GLMs than that of temperature, as $\mathrm{CV}_{\mathrm{GST}}$ was not significant. Given the large spatial scale of this investigation and the relatively high explanatory power of rainfall in the GLMs, these results indicate that precipitation overrides temperature in driving patterns of aboveground NPP. A question naturally follows: why does temporal variation in rainfall, but not in temperature, play a key role in driving aboveground fluctuation in NPP? 

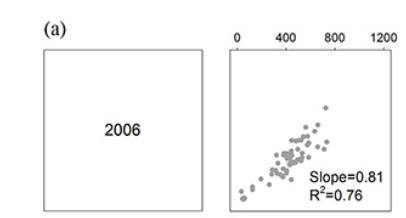

Annual precipitation (mm)
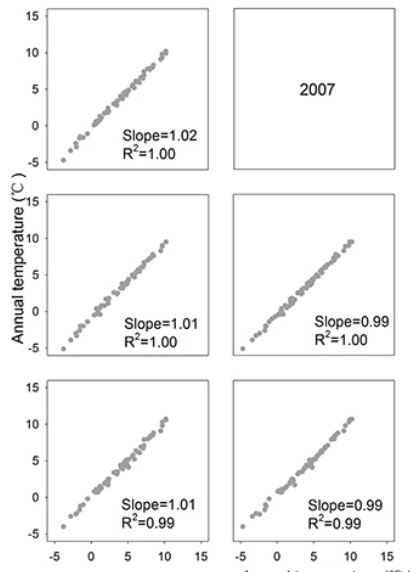
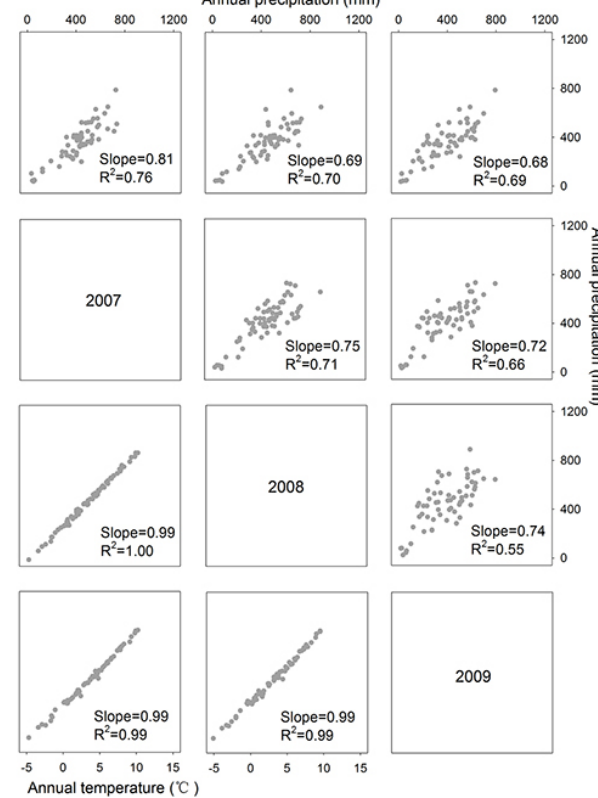
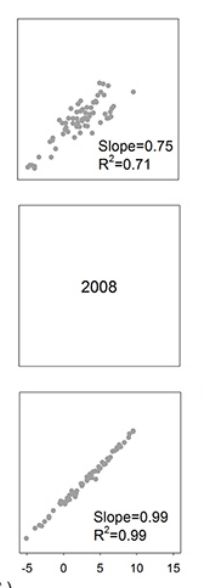

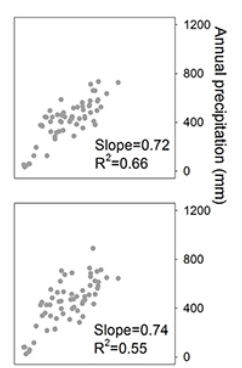

2009
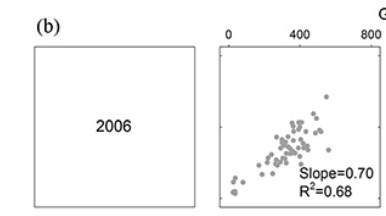

Growing season precipitation $(\mathrm{mm})$
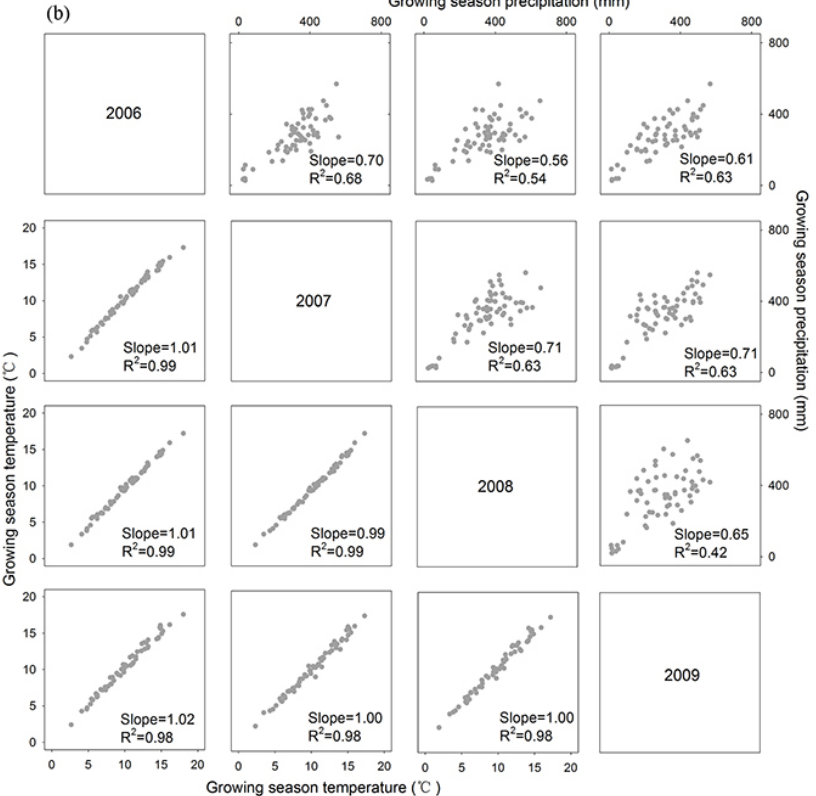

Fig. 4. The results from linear regressions of climate factors for (a) annual climate data and (b) growing season climate data between different years. All relationships are very significant $(P<0.01)$.

It is well known that water is usually a limiting factor for plant growth in grasslands (Sala et al., 1988; Jobbagy et al., 2002; Huxman et al., 2004). Previous studies have demonstrated that the productivity of alpine grasslands is highly responsive to rainfall (Ram et al., 1989; Walker et al., 1994; Song et al., 2008; Yang et al., 2009), indicating the importance of water condition in constraining alpine vegetation production. Particularly, the quantity of rainfall during the growing season greatly influences grassland production (Lauenroth and Sala, 1992; Yang et al., 1998; Nippert et al., 2006; La Pierre et al., 2011). In addition, many alpine species are well adapted to extremely low temperatures and large diurnal temperature ranges (Zhang et al., 1988; Walker et al., 1994; Elmendorf et al., 2012). As several studies have shown, alpine plants are often characterized by low optimal temperature, high temperature adaption, and strong resilience to short-term temperature fluctuations (Billings and Mooney, 1968; Chapin, 1983; Billings, 1987; Beck, 1994; Theurillat and Guisan, 2001; Erschbamer et al., 2009). Hence, as our analysis showed, production in Tibetan alpine grassland ecosystems would be quite constrained by rainfall, especially growing season precipitation, and the temporal variation in precipitation surpasses that of temperature in determining the spatial patterns of NPP. In view of the fact that rainfall on the plateau surface is mainly brought by the warm and humid monsoon from South Asia, we could conclude that the interannual variation in monsoon activity drives the temporal dynamics of community production in the Tibetan alpine grasslands.
Recently, Geng et al. (2012) reported that the large-scale patterns of soil respiration in the Tibetan alpine grasslands are best explained by belowground biomass and soil moisture but not temperature, which affects respiration indirectly by influencing belowground biomass and soil moisture. Considering that decomposition processes are very sensitive to temperature, the results of Geng et al. (2012), together with ours, suggest that differing with other alpine ecosystems, Tibetan alpine grassland ecosystems might be more constrained by water conditions than temperature.

\subsection{The effect of species richness on community stability}

In addition to fluctuations in abiotic conditions, we also found that biodiversity can be associated with the interannual variation of production in alpine grasslands. In previous research, we observed that mean ANPP was positively affected by species richness in these high-altitude grasslands of the Tibetan Plateau (Ma et al., 2010). Here, we found a negative correlation between average species richness and $\mathrm{CV}_{\mathrm{ANPP}}$, and after considering annual climatic fluctuations, the effects of SR were still significant in the first GLM. This contrasts with some experimental studies in which diversity-dependent production decreases the stability of ecosystem functioning (e.g., Pfisterer and Schmid, 2002). To some extent, these results provide field evidence for a positive diversity-stability relationship as has been reported in most studies (e.g., Bai et al., 2004; Tilman et al., 2006; Flynn et al., 2008; Roscher et al., 2011). 

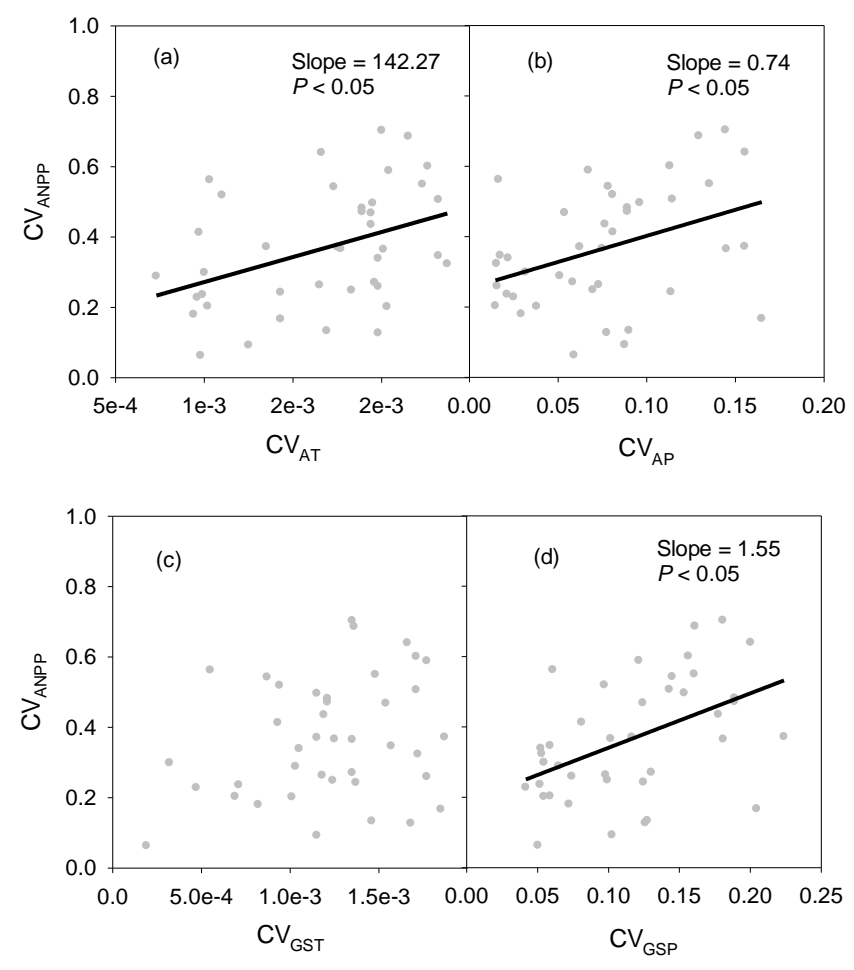

Fig. 5. Linear relationships for $\mathrm{CV}$ of aboveground net primary production (ANPP) with CV of annual temperature (a), CV of annual precipitation (b), $\mathrm{CV}$ of growing season temperature (c), and $\mathrm{CV}$ of growing season precipitation (d) from 2006 to 2009. Significant regression lines at $P<0.05$ are shown.

Both local processes, due to asynchronous population responses (Tilman et al., 2006; Loreau and de Mazancourt, 2008), and regional processes, such as species immigration (Loreau et al., 2003; Staddon et al., 2010), could contribute to the species richness-stability relationship at a large scale. However, considering that the dominant species in alpine ecosystems are perennial (Zhang et al., 1988; Godfree et al., 2004), processes necessary for the spatial insurance effect, such as species dispersal and turnover, would be very slow and unlikely to be observed in a 4-year study. Thus, local processes are probably the main cause of the stabilizing effect of species richness on community productivity in our study.

Furthermore, the $R^{2}$ of the linear regression between species richness and $\mathrm{CV}_{\mathrm{ANPP}}$ was relatively low, and species richness did not have a significant effect in the GLM that used growing season climate data. These results suggest that diversity does not strongly influence community stability. Several studies have reported that in addition to richness, species composition and evenness would also affect community stability (Hector et al., 2011; Sasaki and Lauenroth, 2011). Therefore, it is necessary to choose other aspects of biodiversity to effectively study the diversity-stability relationship at large spatial scales.

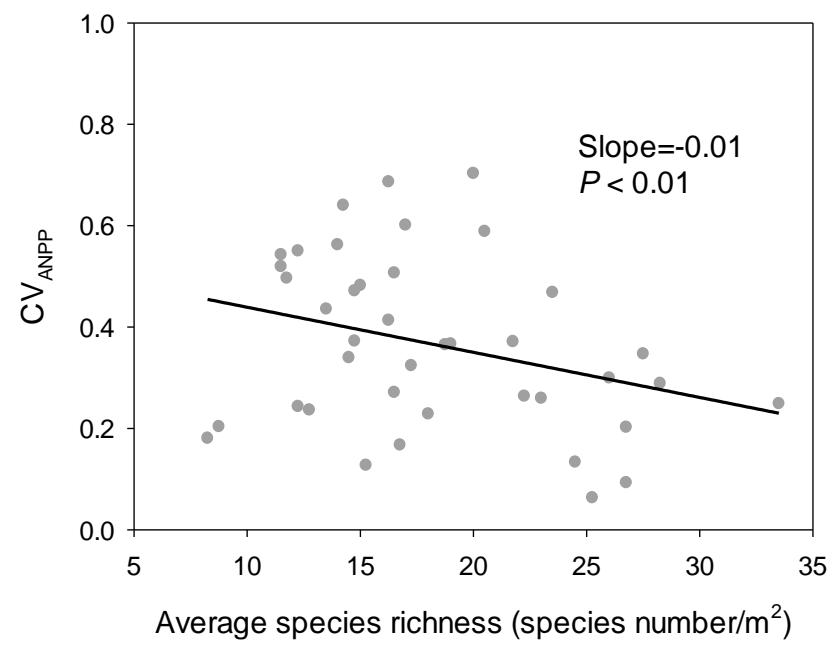

Fig. 6. Linear relationship between 4-year average of species richness and $\mathrm{CV}$ of aboveground net primary production (ANPP).

\subsection{Limitations of the current study}

In the present study, transect surveys over 4 consecutive years were conducted to investigate the interannual variation in community production in the Tibetan alpine grasslands. The results show that, due to the parallel climatic regimes across the plateau, these alpine grasslands are not more sensitive than other grassland types in terms of community production. Tibetan alpine grasslands represent synchronous, regionalscale dynamics of ANPP. However, although climate variations during our study period could represent more than $80 \%$ of the climate fluctuations observed over the past 30 years, our study period might still be too short to explore some characteristics of the temporal variations, such as the spatial insurance effect, in the alpine grasslands. Additionally, although the plateau monsoon could generate parallel climate patterns in different years, extreme climate events may occur and induce deviations from the synchronous pattern. Therefore, the magnitude of uncertainty in the studies based on a 1 -year transect surveys is still unclear.

Another potential limitation in our study could stem from excluding the influences of grazing incompletely. Due to the fact that herbivorous behavior has a major effect on the measurement of ANPP, we located our survey sites either in deferred grazing areas, or on the winter pastures which are free from grazing in growing seasons. However, even if no domestic animals exist, there are still wild animals such as Mongolian gazelle (Procapra gutturosa) and Tibetan antelope (Pantholops hodgsonii) which appear in a number of study sites. Because of the absence of the data, it is very difficult to exclude herbivorous behavior from wild animals. To what extent grazing may affect the interannual variation of ANPP in our study region is still difficult to quantify. 


\section{Conclusions}

Based on a transect survey that used the same protocols for 4 consecutive years, we found that the average ANPP in Tibetan alpine grasslands varied 1.5 -fold with a mean temporal CV of $36.6 \%$ across the 40 sites. Compared with other studies, the magnitude of temporal variation in the alpine grasslands is not larger than those in other grassland types, suggesting that alpine grasslands are not more sensitive to climate fluctuations than other grasslands. Despite the variations in the average value, aboveground NPP exhibited synchronous temporal variation and consistent spatial patterns over the 4-year period because the plateau monsoon system generates parallel climate regimes on the plateau over time. Moreover, surprisingly, we found that rainfall fluctuation had a more profound effect on community production dynamics than temperature variation; variations in monsoon activity drive the interannual variations of aboveground NPP in the Tibetan grasslands. These results will improve our understanding of water deficiency in the Tibetan alpine grasslands. Meanwhile, high species richness significantly reduced variations in aboveground NPP, supporting the idea that diversity can stabilize community production in high-altitude grasslands.

\section{Supplementary material related to this article is available online at http://www.biogeosciences.net/11/ 2003/2014/bg-11-2003-2014-supplement.pdf.}

Acknowledgements. The authors are grateful to Wenjia Zhou and Kuo Yang for assistance with field sampling and to Yao Huang and Wenjuan Sun for accessing the climate data used in the paper. This study was supported by the National Program on Key Basic Research Project (Grant No. 2010CB950602 and 2014CB954004), the National Natural Science Foundation of China (Grant No. 31025005 and 31021001), and the "Strategic Priority Research Program" of the Chinese Academy of Sciences (Grant No. XDA05050304). Dan F. B. Flynn was partially supported by a Research Fellowship for International Young Scientists of the Chinese Academy of Sciences.

Edited by: G. Wohlfahrt

\section{References}

Bai, Y. F., Han, X. G., Wu, J. G., Chen, Z. Z., and Li, L. H.: Ecosystem stability and compensatory effects in the Inner Mongolia grassland, Nature, 431, 181-184, 2004.

Beck, E.: Cold tolerance in tropical alpine plants, in: Tropical Alpine Environments: Plant Form and Function, edited by: Rundel, P. W., Smith, A. P., and Meinzer, F. C., Cambridge University Press, Cambridge, 77-110, 1994.
Billings, W. D.: Constraints to plant growth, reproduction, and establishment in arctic environments, Arctic Alpine Res., 19. 357365, 1987.

Billings, W. D. and Mooney, H. A.: The ecology of arctic and alpine plants, Biological Reviews, 43, 481-529, 1968.

Briggs, J. M. and Knapp, A. K.: Interannual variability in primary production in tallgrass prairie: climate, soil moisture, topographic position, and fire as determinants of aboveground biomass, Am. J. Bot., 82, 1024-1030, 1995.

Cannone, N., Sgorbati, S., and Guglielmin, M.: Unexpected impacts of climate change on alpine vegetation, Front Ecol- Environ-, 5, 360-364, 2007.

Chapin, F. S. III: Direct and indirect effects of temperature on arctic plants, Polar Biology, 2, 47-52, 1983.

Chapin, F. S. III, Matson, P. A., and Mooney, H. A.: Principles of Terrestrial Ecosystem Ecology, Springer-Verlag, New York, USA, 2002.

Chinese Academy of Sciences: Vegetation Atlas of China, Science Press, Beijing, 2001.

Cui, X. and Graf, H. F.: Recent land cover changes on the Tibetan Plateau: a review, Climatic Change, 94, 47-61, 2009.

Culver, D. C., Christman, M. C., Elliott, W. R., Hobbs, H. H., and Reddell, J. R.: The North American obligate cave fauna: regional patterns, Biodivers Conserv, 12, 441-468, 2003.

Diggle, P. K., Lower, S., and Ranker, T. A.: Clonal diversity in alpine populations of polygonum viviparum (polygonaceae), Int. J. Plant. Sci., 159, 606-615, 1998.

Elmendorf, S. C., Henry, G. H. R., Hollister, R. D., Björk, R. G., Boulanger-Lapointe, N., Cooper, E. J., Cornelissen, J. H. C., Day, T. A., Dorrepaal, E., Elumeeva, T. G., Gill, M., Gould, W. A., Harte, J., Hik, D. S., Hofgaard, A., Johnson, D. R., Johnstone, J. F., Jónsdóttir, I. S., Jorgenson, J. C., Klanderud, K., Klein, J. A., Koh, S., Kudo, G., Lara, M., Lévesque, E., Magnusson, B., May, J. L., Mercado-Díaz, J. A., Michelsen, A., Molau, U., MyersSmith, I. H., Oberbauer, S. F., Onipchenko, V. G., Rixen, C., Martin Schmidt, N., Shaver, G. R., Spasojevic, M. J., Pórhallsdóttir, ?. E., Tolvanen, A., Troxler, T., Tweedie, C. E., Villareal, S., Wahren, C.-H., Walker, X., Webber, P. J., Welker, J. M., and Wipf, S.: Plot-scale evidence of tundra vegetation change and links to recent summer warming, Nature Clim. Change, 2, 453457, 2012.

Erschbamer, B., Kiebacher, T., Mallaun, M., and Unterluggauer, P.: Short-term signals of climate change along an altitudinal gradient in the South Alps, Plant Ecol., 202, 79-89, 2009.

Fan, J., Wang, K., Harris, W., Zhong, H., Hu, Z., Han, B., Zhang, W., and Wang, J.: Allocation of vegetation biomass across a climate-related gradient in the grasslands of Inner Mongolia, J. Arid. Environ., 73, 521-528, 2009.

Field, C. B., Behrenfeld, M. J., Randerson, J. T., and Falkowski, P.: Primary production of the biosphere: integrating terrestrial and oceanic components, Science, 281, 237-240, 1998.

Flynn, D. F. B., Schmid, B., He, J.-S., Wolfe-Bellin, K. S., and Bazzaz, F. A.: Hierarchical reliability in experimental plant assemblages, J. Plant Ecol., 1, 59-65, 2008.

Gao, Q., Li, Y., Wan, Y., Qin, X., Jiangcun, W., and Liu, Y.: Dynamics of alpine grassland NPP and its response to climate change in Northern Tibet, Clim. Change, 97, 515-528, 2009.

Geng, Y., Wang, Y., Yang, K., Wang, S., Zeng, H., Baumann, F., Kühn, P., Scholten, T., and He, J.-S.: Soil respiration in Tibetan 
alpine grasslands: belowground biomass and soil moisture, but not soil temperature, best explain the large-scale patterns, Plos One, 7, e34968, doi:10.1371/journal.pone.0034968, 2012.

Godfree, R., Lepschi, B., and Mallinson, D.: Ecological filtering of exotic plants in an Australian sub-alpine environment, J. Veg. Sci., 15, 227-236, 2004.

He, J.-S., Wang, X., Flynn, D. F. B., Wang, L., Schmid, B., and Fang, J. Y.: Taxonomic, phylogenetic, and environmental tradeoffs between leaf productivity and persistence, Ecology, 90, 2779-2791, 2009.

Hector, A., Bell, T., Hautier, Y., Isbell, F., Kéry, M., Reich, P. B., van Ruijven, J., and Schmid, B.: Bugs in the analysis of biodiversity experiments: species richness and composition are of similar importance for grassland productivity, Plos One, 6, e17434, doi:10.1371/journal.pone.0017434, 2011.

Hu, Z. M., Fan, J. W., Zhong, H. P., and Yu, G. R.: Spatiotemporal dynamics of aboveground primary productivity along a precipitation gradient in Chinese temperate grassland, Science in China Series D, Earth Sci., 50, 754-764, 2007.

Hui, D. and Jackson, R. B.: Geographical and interannual variability in biomass partitioning in grassland ecosystems: a synthesis of field data, New Phytol, 169, 85-93, 2006.

Huston, M. A. and Wolverton, S.: The global distribution of net primary production: resolving the paradox, Ecol. Monogr., 79, 343-377, 2009.

Huxman, T. E., Snyder, K. A., Tissue, D., Leffler, A. J., Ogle, K., Pockman, W. T., Sandquist, D. R., Potts, D. L., and Schwinning, S.: Precipitation pulses and carbon fluxes in semi-arid and arid ecosystems, Oecologia, 141, 254-268, 2004.

Jobbágy, E. G., Sala, O. E., and Paruelo, J. M.: Patterns and controls of primary production in the Patagonian steppe: a remote sensing approach, Ecology, 83, 307-319, 2002.

Körner, C.: Alpine Plant Life: Functional Plant Ecology of High Mountain Ecosystems, 2nd Edn., Springer-Verlag, Berling, 2003.

Körner, C., Diemer, M., Schäppi, B., Niklaus, P., and Arnone, J.: The responses of alpine grassland to four seasons of $\mathrm{CO}_{2}$ enrichment: a synthesis, Acta Oecol., 18, 165-175, 1997.

Knapp, A. K. and Smith, M. D.: Variation among biomes in temporal dynamics of aboveground primary production, Science, 291, 481-484, 2001.

Knapp, A. K., Fay, P. A., Blair, J. M., Collins, S. L., Smith, M. D., Carlisle, J. D., Harper, C. W., Danner, B. T., Lett, M. S., and McCarron, J. K.: Rainfall variability, carbon cycling, and plant species diversity in a mesic grassland, Science, 298, 2202-2205, 2002.

La Pierre, K. J., Yuan, S., Chang, C. C., Avolio, M. L., Hallett, L. M., Schreck, T., and Smith, M. D.: Explaining temporal variation in above-ground productivity in a mesic grassland: the role of climate and flowering, J. Ecol., 99, 1250-1262, 2011.

Lauenroth, W.: Grassland primary production: North American grasslands in Perspective, in: Perspectives in Grassland Ecology, edited by: French, N., Ecological Studies, Springer New York, 3-24, 1979.

Lin, Z. and Zhao, X.: Spatial characteristics of changes in temperature and precipitation of the Qinghai-Xizang (Tibet) Plateau, Science in China Series D, Earth Sci., 39, 442-448, 1996.

Loewen, M., Kang, S., Armstrong, D., Zhang, Q., Tomy, G., and Wang, F.: Atmospheric transport of mercury to the Tibetan Plateau, Environ. Sci. Technol., 41, 7632-7638, 2007.
Loreau, M. and de Mazancourt, C.: Species synchrony and its drivers: neutral and nonneutral community dynamics in fluctuating environments, The American Naturalist, 172, E48-E66, 2008.

Loreau, M., Mouquet, N., and Gonzalez, A.: Biodiversity as spatial insurance in heterogeneous landscapes, Proc. Natl. Ac. Sci., 100, 12765-12770, 2003.

Lu, H. Y., Wang, X. Y., Ma, H. Z., Tan, H. B., Vandenberghe, J., Miao, X. D., Li, Z., Sun, Y. B., An, Z. S., and Cao, G. C.: The plateau monsoon variation during the past $130 \mathrm{kyr}$ revealed by loess deposit at northeast Qinghai-Tibet (China), Global Planet. Change, 41, 207-214, 2004.

Luo, T., Pan, Y., Ouyang, H., Shi, P., Luo, J., Yu, Z., and Lu, Q.: Leaf area index and net primary productivity along subtropical to alpine gradients in the Tibetan Plateau, Global Ecol. Biogeogr., 13, 345-358, 2004.

Luo, T., Zhang, L., Zhu, H., Daly, C., Li, M., and Luo, J.: Correlations between net primary productivity and foliar carbon isotope ratio across a Tibetan ecosystem transect, Ecography, 32, 526538, 2009.

Ma, W., He, J.-S., Yang, Y., Wang, X., Liang, C., Anwar, M., Zeng, H., Fang, J. Y., and Schmid, B.: Environmental factors covary with plant diversity-productivity relationships among Chinese grassland sites, Global Ecol. Biogeogr., 19, 233-243, 2010 a.

Ma, W., Liu, Z., Wang, Z., Wang, W., Liang, C., Tang, Y., He, J.S., and Fang, J. Y.: Climate change alters interannual variation of grassland aboveground productivity: evidence from a 22-year measurement series in the Inner Mongolian grassland, J. Plant. Res., 123, 509-517, 2010b.

McNaughton, S. J., Oesterheld, M., Frank, D. A., and Williams, K.: Ecosystem-level patterns of primary productivity and herbivory in terrestrial habitats, 1989.

Muldavin, E. H., Moore, D. I., Collins, S. L., Wetherill, K. R., and Lightfoot, D. C.: Aboveground net primary production dynamics in a northern Chihuahuan Desert ecosystem, Oecologia, 155, 123-132, 2008.

Niklaus, P. A., Leadley, P. W., Schmid, B., and Körner, C.: A longterm field study on biodiversity $\times$ elevated $\mathrm{CO}_{2}$ interactions in grassland, Ecol. Monogr., 71, 341-356, 2001.

Nippert, J. B., Knapp, A. K., and Briggs, J. M.: Intra-annual rainfall variability and grassland productivity: can the past predict the future?, Plant. Ecol., 184, 65-74, 2006.

Oesterheld, M., Loreti, J., Semmartin, M., and Sala, O. E.: Interannual variation in primary production of a semi-arid grassland related to previous-year production, J. Veg. Sci., 12, 137-142, 2001.

Parton, W. J., Scurlock, J. M. O., Ojima, D. S., Schimel, D. S., Hall, D. O., and Scopegram Group, M.: Impact of climate change on grassland production and soil carbon worldwide, Glob. Change Biol., 1, 13-22, 1995.

Pauli, H., Gottfried, M., and Grabherr, G.: Effects of climate change on the alpine and nival vegetation of the Alps, J. Moutain Ecol., 7, 9-12, 2003.

Pfisterer, A. B., Joshi, J., Schmid, B., and Fischer, M.: Rapid decay of diversity-productivity relationships after invasion of experimental plant communities, Basic Appl. Ecol., 5, 5-14, 2004.

Piao, S. L., Fang, J. Y., and He, J.-S.: Variations in vegetation net primary production in the Qinghai-Xizang Plateau, China, from 1982 to 1999, Clim. Change, 74, 253-267, 2006. 
Qian, W. and Zhu, Y.: Climate change in China from 1880 to 1998 and its impact on the environmental condition, Clim. Change, 50, 419-444, 2001.

R Development Core Team: R: A language and environment for statistical computing, R Foundation for Statistical Computing, Vienna, Austrilia, 2011.

Ram, J., Singh, J., and Singh, S.: Plant biomass, species diversity and net primary production in a central Himalayan high altitude grassland, J. Ecol., 77, 456-468, 1989.

Roscher, C., Weigelt, A., Proulx, R., Marquard, E., Schumacher, J., Weisser, W. W., and Schmid, B.: Identifying population- and community-level mechanisms of diversity-stability relationships in experimental grasslands, J. Ecol., 99, 1460-1469, 2011.

Sala, O. E., Parton, W., Joyce, L., and Lauenroth, W.: Primary production of the central grassland region of the United States, Ecology, 69, 40-45, 1988.

Sala, O. E., Chapin, F. S. III, Armesto, J. J., Berlow, E., BloomField, J., Dirzo, R., Huber-Sanwald, E., Huenneke, L. F., Jackson, R. B., Kinzig, A., Leemans, R., Lodge, D. M., Mooney, H. A., Oesterheld, M., Poff, N. L., Sykes, M. T., Walker. B. H., Walker, M., and Wall, D. H.: Global biodiversity scenarios for the year 2100, Science, 287, 1770-1774, 2000.

Sasaki, T. and Lauenroth, W. K.: Dominant species, rather than diversity, regulates temporal stability of plant communities, Oecologia, 166, 761-768, 2011.

Schäppi, B.: Growth dynamics and population development in an alpine grassland under elevated $\mathrm{CO}_{2}$, Oecologia, 106, 93-99, 1996.

Schäppi, B. and Körner, C.: Growth responses of an alpine grassland to elevated $\mathrm{CO}_{2}$, Oecologia, 105, 43-52, 1996.

Scurlock, J. M. O. and Hall, D. O.: The global carbon sink: a grassland perspective, Glob. Change Biol., 4, 229-233, 1998.

Shaver, G. R. and Jonasson, S.: Response of Arctic ecosystems to climate change: results of long-term field experiments in Sweden and Alaska, Polar Res., 18, 245-252, 1999

Shaw, M. R., Zavaleta, E. S., Chiariello, N. R., Cleland, E. E., Mooney, H. A., and Field, C. B.: Grassland responses to global environmental changes suppressed by elevated $\mathrm{CO}_{2}$, Science, 298, 1987-1990, 2002.

Song, M., Duan, D., Chen, H., Hu, Q., Zhang, F., Xu, X., Tian, Y., Ouyang, H., and Peng, C.: Leaf $\delta^{13} \mathrm{C}$ reflects ecosystem patterns and responses of alpine plants to the environments on the Tibetan Plateau, Ecography, 31, 499-508, 2008.

Staddon, P., Lindo, Z., Crittenden, P. D., Gilbert, F., and Gonzalez, A.: Connectivity, non-random extinction and ecosystem function in experimental metacommunities, Ecol. Lett., 13, 543-552, 2010.

Stoch, F., Artheau, M., Brancelj, A., Galassi, D. M. P., and Malard, F.: Biodiversity indicators in European ground waters: towards a predictive model of stygobiotic species richness, Fresh. Biol., 54, 745-755, 2009.

Theurillat, J. P. and Guisan, A.: Potential impact of climate change on vegetation in the European Alps: a review, Clim. Change, 50, 77-109, 2001.

Tian, H., Melillo, J. M., Kicklighter, D. W., McGuire, A. D., Helfrich, J. V., Moore, B., and Vörösmarty, C. J.: Effect of interannual climate variability on carbon storage in Amazonian ecosystems, Nature, 396, 664-667, 1998.
Tian, L., Yao, T., MacClune, K., White, J., Schilla, A., Vaughn, B., Vachon, R., and Ichiyanagi, K.: Stable isotopic variations in west China: a consideration of moisture sources, J. Geophys. Res., 112, D10112, doi:10.1029/2006JD007718, 2007.

Tilman, D., Reich, P. B., and Knops, J. M. H.: Biodiversity and ecosystem stability in a decade-long grassland experiment, Nature, 441, 629-632, 2006.

Van Wijk, M., Clemmensen, K. E., Shaver, G., Williams, M., Callaghan, T., Chapin III, F. S., Cornelissen, J., Gough, L., Hobbie, S., Jonasson, S., Lee, J. A., Michelsen, A., Press, M. C., Richardson, S. J., and Rueth, H.: Long-term ecosystem level experiments at Toolik Lake, Alaska, and at Abisko, Northern Sweden: generalizations and differences in ecosystem and plant type responses to global change, Glob. Change Biol., 10, 105-123, 2004.

Walker, M. D., Webber, P. J., Arnold, E. H., and Ebert-May, D.: Effects of interannual climate variation on aboveground phytomass in alpine vegetation, Ecology, 75, 393-408, 1994.

Walker, M. D., Wahren, C. H., Hollister, R. D., Henry, G. H. R., Ahlquist, L. E., Alatalo, J. M., Bret-Harte, M. S., Calef, M. P., Callaghan, T. V., Carroll, A. B., Epstein, H. E., Jónsdóttir, I. S., Klein, J. A., Magnússon, B., Molau, U., Oberbauer, S. F., Rewa, S. P., Robinson, C. H., Shaver, G. R., Suding, K. N., Thompson, C. C., Tolvanen, A., Totland, Ø., Turner, P. L., Tweedie, C. E., Webber, P. J., and Wookey, P. A.: Plant community responses to experimental warming across the tundra biome, P. Natl. Acad. Sci. USA, 103, 1342-1346, 2006.

Wang, W., Wang, Q., Li, S., and Wang, G.: Distribution and species diversity of plant communities along transect on the northeastern Tibetan Plateau, Biodiversity \& Conservation, 15, 1811-1828, 2006.

Weber, U., Jung, M., Reichstein, M., Beer, C., Braakhekke, M. C., Lehsten, V., Ghent, D., Kaduk, J., Viovy, N., Ciais, P., Gobron, N., and Odenbeck, C. R.: The interannual variability of Africa's ecosystem productivity: a multi-model analysis, Biogeosciences, 6, 285-295, 2009, http://www.biogeosciences.net/6/285/2009/.

Wielgolaski, F. and Karlsen, S.: Some views on plants in polar and alpine regions, Reviews in Environmental Science and Biotechnology, 6, 33-45, 2007.

Williams, M. and Rastetter, E. B.: Vegetation characteristics and primary productivity along an arctic transect: implications for scaling-up, J. Ecol., 87, 885-898, 1999.

$\mathrm{Xu}, \mathrm{Z}$. X., Gong, T. L., and Li, J. Y.: Decadal trend of climate in the Tibetan Plateau: regional temperature and precipitation, Hydrol. Proc., 22, 3056-3065, 2008.

Yang, L., Wylie, B. K., Tieszen, L. L., and Reed, B. C.: An analysis of relationships among climate forcing and time-integrated NDVI of grasslands over the U.S. northern and central Great Plains, Rem. Sens. Environ., 65, 25-37, 1998.

Yang, Y. H., Fang, J. Y., Tang, Y. H., Ji, C. J., Zheng, C. Y., He, J.-S., and Zhu, B.: Storage, patterns and controls of soil organic carbon in the Tibetan grasslands. Global Change Biology, 14, 1592-1599, 2008a.

Yang, Y. H., Fang, J. Y., Ma, W., and Wang, W.: Relationship between variability in aboveground net primary production and precipitation in global grasslands, Geophys. Res. Lett., 35, L23710, doi:10.1029/2008GL035408, 2008b. 
Yang, Y. H., Fang, J. Y., Pan, Y. D., and Ji, C. J.: Aboveground biomass in Tibetan grasslands, J Arid Environ, 73, 91-95, 2009.

Zhang, J., Wang, J. T., Chen, W., Li, B., and Zhao, K.: Vegetation of Xizang (Tibet), Science Press, Beijing, China, 1988 (in Chinese). Zhang, Y. and Welker, J. M.: Tibetan alpine tundra responses to simulated changes in climate: aboveground biomass and community responses, Arctic Alpine Res., 28, 203-209, 1996.
Zhao, M. and Running, S. W.: Drought-induced reduction in global terrestrial net primary production from 2000 through 2009, Science, 329, 940-943, 2010.

Zhong, L., Ma, Y., Salama, M. S., and Su, Z.: Assessment of vegetation dynamics and their response to variations in precipitation and temperature in the Tibetan Plateau, Clim. Change, 103, 519535, 2010. 